\title{
Rat Mesenchymal Stem Cells from Adipose Tissue Reduce Bleomycin-Induced Lung Remodeling in Late Stage
}

\author{
Renato Gonçalves Felix ${ }^{1}$, Alexandre Todorovic Fabro², Josy Campanhã Vicentini-Oliveira ${ }^{3}$, \\ Ednelson Henrique Bianchi' ${ }^{4}$, Marjorie de Assis Golim ${ }^{5}$, Ondina Silvia Cotrim ${ }^{3}$, \\ João Tadeu Ribeiro-Paes ${ }^{6}$, Elenice Deffune ${ }^{7}$ \\ ${ }^{1}$ Department of Pediatrics, Botucatu Medical School, São Paulo State University, Botucatu, Brazil \\ ${ }^{2}$ Department of Pathology, Botucatu Medical School, São Paulo State University, Botucatu, Brazil \\ ${ }^{3}$ Cell Engineering Lab., Botucatu Medical School, São Paulo State University, Botucatu, Brazil \\ ${ }^{4}$ Animals Lab., Botucatu Medical School, São Paulo State University, Botucatu, Brazil \\ ${ }^{5}$ Flow Cytometry Lab, Botucatu Medical School, São Paulo State University, Botucatu, Brazil \\ ${ }^{6}$ Lab. of Genetics and Cell Therapy, São Paulo State University, Assis, Brazil \\ ${ }^{7}$ Cell Eng.Lab., Botucatu Medical School, São Paulo State University, Botucatu, Brazil \\ Email: rgfelix2005@hotmail.com, alexandretodo@gmail.com,josycv1@yahoo.com.br, votado@bol.com.br, \\ marjorie@fmb.unesp.br, espanhola.btu@gmail.com,jtrpaes@yahoo.com.br, ed12@fmb.unesp.br
}

Received 4 November 2015; accepted 9 January 2016; published 12 January 2016

Copyright (C) 2016 by authors and Scientific Research Publishing Inc.

This work is licensed under the Creative Commons Attribution International License (CC BY). http://creativecommons.org/licenses/by/4.0/

(c) (7) Open Access

\begin{abstract}
Idiopathic pulmonary fibrosis (IPF) is progressive fibrosing interstitial pneumonia of unknown cause, chronic and incurable interstitial lung disease, associated with high mortality rates and unresponsive to treatments currently available. The prevalence of IPF is estimated at approximately 20/100,000 in men and 13/100,000 in women, and the mean age at the time of diagnosis is 67 years and the median survival is $\mathbf{2}$ to 5 years. Therapies available to date, proved, therefore, only palliative measures with doubtful or unsatisfactory result. Many experimental models of pulmonary fibrosis are described. Bleomycin-induced pulmonary fibrosis is a widely used experimental model to identify and validate new therapeutic targets. We have induced pulmonary fibrosis by intratracheal bleomycin and late instillation of mesenchymal stem cells (MSC) from adipose tissue as a therapeutic proposal was used. MSC have the capacity to modulate inflammatory and immune response. Furthermore, the long-term effect of MSCs could also regulate and control to collagen deposition of the myofibroblasts, a final and pivo cell of pulmonary fibrosis. MSC from adipose tissue is an effective therapy to decrease collagen synthesis and expression in late stage of bleomycin-induced pulmonary fibrosis model, which may contribute to new therapeutic targets.
\end{abstract}

How to cite this paper: Felix, R.G., Fabro, A.T., Vicentini-Oliveira, J.C., Bianchi, E.H., de Assis Golim, M., Cotrim, O.S., RibeiroPaes, J.T. and Deffune, E. (2016) Rat Mesenchymal Stem Cells from Adipose Tissue Reduce Bleomycin-Induced Lung Remodeling in Late Stage. Stem Cell Discovery, 6, 24-38. http://dx.doi.org/10.4236/scd.2016.61003 


\section{Keywords}

\section{Mesenchymal Stem Cell, Idiopatic Lung Fibrosis, Animal Models, Treatments}

\section{Introduction}

Idiopathic pulmonary fibrosis (IPF) is a non-neoplastic lung disease characterized by the formation of scar tissue in the lungs, in the absence of any known provocation. It is a rare disease that affects about 5 million people worldwide [1].

The estimated prevalence of the IPF is approximately 20/100,000 13/100,000 in men and women [2]. The mean age at diagnosis is 66 years and the median survival is 2 to 5 years [3]. The IPF presents with clinical picture of gradual onset of dyspnea with or without dry cough, and patients may present digital clubbing and crackles during inspiration. Although some environmental factors (smoking, exposure to silica and livestock) are associated with the disease, the etiology remains unknown [1].

Typical radiological images show basal and peripheral reticular opacities associated with bronchiectasis and standard on "honey-comb". The diagnosis of IPF requires correlation of the clinical picture, changing radiographic images and a lung biopsy [4].

The evaluation by pulmonary function tests, in most cases, shows a restrictive ventilatory defect associated with the reduction of carbon monoxide diffusion and hypoxemia exacerbated or caused by exercise [5].

The clinical treatment of IPF includes anti-inflammatory drugs (steroids), anti-fibrotic agents, immunomodulatory and cytotoxic drugs (cyclophosphamide, azathioprine) associated with partial and temporary improvements. Other support measures include: treatment of complications, such as heart failure and infections, rehabilitation and oxygen therapy [5] [6]. The surgical approach to FPI basically comprises lung transplantation [7]. The different clinical therapeutic approaches, associated with pulmonary rehabilitation techniques, have undeniably contributed to the extension and improvement in quality of life of patients with IPF [8] [9]. Despite significant advances resulting from the introduction of new therapeutic approaches and rehabilitation not managed to present a form of effective treatment, other than just palliative. Lung transplantation, in turn, is rare due to the shortage of donors [10]. Considering these aspects, the social and family impact due to this pathological condition, several experimental models have been proposed, aiming to advance the knowledge on the pathophysiological processes and new therapeutic approaches to IPF [11] [12]. Cell therapy (CT) stem cells (SC) in this context are presented as a therapeutic alternative with great potential applicability in pulmonary fibrosis. There is an extensive literature reporting promising results and therapeutic perspectives with adult stem cells (ASC) and embryonic stem cells (ESC) in the regeneration and repair of organs, including the lung tissue [13]-[18]. Based on this evidence, it is proposed in this project, the use of allogeneic stem cells obtained from adipose tissue for the treatment of fibrosis in rat experimental model.

\subsection{Relevance}

Cell therapy is one of the most interesting topics of biomedical research today and offers support for the socalled regenerative medicine [19]-[21]. The highlight for research on stem cells derived from information that challenge well-established biological concepts and hope that research results can be applied to repair lesions in human tissues. Considering the importance of these issues, this study proposes the use of stem cells from adipose tissue for the treatment of pulmonary fibrosis [22]-[24].

\subsection{Goals}

- To assess the contribution of cell therapy in an animal model of pulmonary fibrosis

- Specific

- Establish animal model of pulmonary fibrosis in albino Wistar rats

- Expand and characterize stem cells from adipose tissue autologous

- To infuse intravenously (caudal vein) and monitor the recovery of the lung tissue 


\section{Material and Methods}

\subsection{Animals}

Will be used 56 male albino Wistar rats (average weight $250 \mathrm{~g}, 8$ weeks old) coming from the Central Animal Laboratory of the Faculty of Medicine of Botucatu, UNESP and approved by the Institutional Laboratory Animal Care and Use Committee (Protocols CEEA 852/2010). The animals will be kept in polypropylene boxes coated with sawdust, in rooms with controlled temperature and light $\left(22^{\circ} \mathrm{C}\right.$ and $12 \mathrm{~h}-12 \mathrm{~h}$ light and dark, respectively). During the period of the experiment, the rats receive solid diet and water supplemented with vitamin ad libitum.

\subsection{Induction of Experimental Lung Fibrosis}

For induction of pulmonary fibrosis in rats, will be used the experimental model proposed by Punithavathi et al., 2000 [25]. Bleomycin is an antineoplastic antibiotic extracted as fermentation product of the fungus "Streptomyces verticillus", with important clinical use in the treatment of various cancer lymphomas and sarcomas. The experimental use of bleomycin lies in the fact that during chemotherapy was realized that between $4 \%-10 \%$ of patients had pulmonary toxicity drugs and this resulted in pulmonary fibrosis process [26]. The use of bleomycin by intratracheal instillation in rats was performed pioneering way in 1979 [27] and generated a reliable model is often used, in view of the development of pulmonary fibrosis capability of rapid and predictable manner.

After single dose intratracheal instillation of bleomycin, one can see three different stages of evolution: the first stage (acute stage of inflammation) corresponding to the first seven days after instillation when there is migration of inflammatory cells, interstitial edema and alveoli in addition activation of mediators of inflammation. In the second stage (stage subacute) that lasts from the 7th to 15th day after installation, realizes an intense inflammation with increased cuboidal epithelial cells in order to repair the attacked epithelium and is noted also the presence of pulmonary fibrosis. In the third stage (resolution stage) which lasts from 15 to 30 days after instillation, inflammation decreases and is noticeable alveolar epithelialization and collagen deposition in the granulation tissue with the formation of fibrosis in the lung. It is understood to 14 days after instillation as the best to measure the process of fibrosis in view of the extensive fibrosis above, but with less variability in fibrotic response [28]. Crutoneo et al. (2006) describe the use of bleomycin to produce the IPF stimulates the pro-fibrotic growth factor TGF-B1, which is considered one of the most important in fibrogenesis. This factor is produced by fibroblast and myofibroblasts [29] [30].

\subsection{Collection, Processing and Characterization of Adipose Tissue Stem Cells}

Study design-intravenous injections of MSC were given $14 \mathrm{~d}$ after bleomycin instillation, in collagen production peak, and rats were sacrified after 2 weeks. To obtain allogenic MSCs from adipose tissue blocks of 5 different animals were used. After removing a sample of $3.35 \mathrm{~g}$ of adipose tissue as preceded dissociation with collagenase type I. We obtained $5.3 \times 10^{4}$ lymphomononuclear cells/g of adipose tissue. These cells were expanded in culture for 21 days Knockout DMEM-F12 medium added with 10\% fetal bovine serum. Three criteria were considered proof of MSC: adhesion to plastic, expression of CD90 by flow cytometry and the ability to differentiate into three lineages of mesodermal origin [18]-[21]. It performed a pool of 5 samples at a final concentration $10^{6}$ cells for intravenous injection. A total of 60 male rats, albino Wistar rats, weighing $250 \mathrm{~g}$ aged 8 weeks. Wistar mice were treated with (BLM-W, $\mathrm{n}=15)$ intratracheal bleomycin $(1.5 \mathrm{U} / \mathrm{kg})$ or $(\mathrm{CTR}-\mathrm{W}, \mathrm{n}=15)$ placebo. At 14 day $1 \times 10^{6}$ MSCs were infused into half of placebo (CTR-MSC, $n=15$ ) and half of bleomycintreated mice (BLM-MSC, $\mathrm{n}=15)$. Four experimental groups being monitored: weight and saturation index in 3 stages: D0, D14 and D28. In D0 was performed instillation of bleomycin at a dose of $1.5 \mathrm{U} / \mathrm{Kg}$. In D14 infusion of mesenchymal stem cells quantified and phenotyped by flow cytometry. In D28 was the sacrifice of animals for macro and microscopic analyzes. The lung was fixed and 3-mm sections were stained with Hematoxylin \& Eosine and Picro-sirius Red staining. Quantification and morphometric analysis was performed by two doubleblind pathologists and by image analysis following a conventional stereological method, as recommended by ATS/ERS standards for quantitative assessment of lung structure [23] [24].

Taking into consideration the leaflet involved in embryonic lung origin of the cells it was decided to obtain adipose tissue abdominal wall for processing and characterization of stem cells. The adipose tissue (AT) emerges in the last 5 years as a promising source for cell therapy CT. The AT collection site was set according to prelim- 
inary results of Cell Engineering Laboratory of the Blood Center of Botucatu (CELab) which shows that the tissue obtained from the abdomen of AT present growth curve above the AT obtained from other parts of the body.

After anesthetizing the animals with $30 \mathrm{mg} / \mathrm{kg}$ of thiopental sodium $2.5 \%$, intraperitoneal (IP), they are placed in a laminar flow HEPA filter to make the removal of the AT fragment. Proceeds to antisepsis of the hair, opening $2-3 \mathrm{~cm}$ skin, AT identification and removal fragment with an average weight of $4 \mathrm{~g}$. The AT fragment is washed thoroughly with $0.9 \%$ saline $(100-200 \mathrm{ml})$ and then placed in a sterile conical tube containing HEPES medium $\left(\right.$ Life Technologies ${ }^{\circledR}$ ) transport with antibiotics type penicillin and streptomycin (Life Technologies ${ }^{\circledR}$ ). It will be packaged in polystyrene boxes and transported to CELab. Upon receiving the material, the adipose tissue is heavy undergoing washing in PBS buffer suffered further incubation with collagenase type I (Sigma Aldrich ${ }^{\circledR}$ ) at rest for 12 hours in oven at $37^{\circ} \mathrm{C}$. It blocks the reaction with fetal bovine serum for 5 minutes, and transferred to the material $15 \mathrm{ml}$ conical tube. It was centrifuged at $700 \mathrm{~g}$ for 10 minutes, the supernatant aspirated, the pellet dissolved in PBS and centrifuged again for complete removal of the enzyme. In a Neubauer chamber determines the viability and cell count by exclusion method of trypan blue dye $\left(\operatorname{Invitrogen}{ }^{\circledR}\right)$. An aliquot of cells is taken to characterization by flow cytometry using the markers: CD90, CD44 (positive marker) and CD34, CD14 or 45 as negative markers. The cells were seeded in in T-flasks $25 \mathrm{~cm}^{2}\left(10^{5} \mathrm{cells} / \mathrm{cm}^{2}\right)$. After 5 days (establishment of the adherent mesenchymal stem cell colonies) return to the DMEM-Ham F12-based medium supplemented with Knockout Serum Replacement, nonessential amino acids, 2-mercaptoethanol, and Glutamax (life Technologies $\left.{ }^{\circledR}\right)(5 \mathrm{ml})$ every two days. At this time, the cells will again be subjected to enzymatic processing and new rate will be processed by flow cytometry using the same markers. Comet test and micronucleus will monitor any DNA damage determined by cell culture. The analysis was performed on a FACSCalibur cytometer of $\mathrm{BD}{ }^{\circledR}$ flow through reading in Cell Quest Software Pro ${ }^{\circledR}$. Importantly, MSC were plated amplified by the 4th passage to obtain the appropriate number of cells for the experiment, with the same stored frozen in liquid nitrogen.

\subsection{Groups}

The animals were divided into 4 groups of 15 animals, kept under strict control by veterinarian during the 28 days of observation from the date of tracheal instillation of bleomycin or saline, Table 1.

The 4 groups were formed as:

Group 1 BLM-W = fibrosis control. Wistar mice instilled with bleomycin solution and "treated" with physiological serum, Table 1.

Group 2 CTR - W = animals controls: Wistar mice instilled with saline and "treated" with saline (placebo).

Group 3 BLM-MSC = study group: Wistar mice instilled with bleomycin solution and treated with MSC obtained from adipose tissue.

Group 4 CTR-MSC = MSC control action: Wistar mice control group instilled with saline and treated with MSC stem cells obtained from adipose tissue.

All animals were subjected to the same stress level in handling and receiving in the $14^{\circ}$ day after bleomycin intravenous infusion procedure with MSC or saline.

\subsection{Mesenchymal Stem Cell Infunsion (MISI)}

Cell transplantation was performed on the 30th day after intratracheal instillation of bleomycin solution. The infusion of MSC was performed by intravenous (tail vein). The group treated with MSC was infused with $0.4 \mathrm{ml}$ of the diluted cell solution in DMEM at a concentration of $1 \times 10^{6} / \mathrm{ml}$.

Table 1. Constitution of study groups, induction of fibrosis and treatment.

\begin{tabular}{cccccc}
\hline Group & Instillation Day & Instilled Solution & Infusion Day & $\begin{array}{c}\text { Infused Solution } \\
\text { Treatment IV }\end{array}$ & Sacrifice Day \\
\hline G1 BLM-W & 0 & Bleomycin & $14^{\circ}$ & Saline & $28^{\circ}$ \\
G2 CTR-W & 0 & Saline & $14^{\circ}$ & Saline & $28^{\circ}$ \\
G3 BLM-MSC & 0 & Bleomycin & $14^{\circ}$ & MSC & $28^{\circ}$ \\
G4 CTR-MSC & 0 & Saline & $14^{\circ}$ & MSC & $28^{\circ}$ \\
\hline
\end{tabular}




\subsection{Macroscopic and Microscopic Analysis}

Once the animals sacrificed on $\mathrm{D}+28$, after determining the saturation measurement and weighing the same, the lungs were transported in labeled tubes in sequential numerical order to the Pathology Service. The material was analyzed by two different pathologists double blind study. After processing the lungs, always having been processed the same lobe, namely, right middle lobe, the remainder was kept preserved for possible analysis. After proceedings the material was proceeded the hematoxylin-eosin and Picrosirius. For the evaluation was established by pathologists semi-quantitative classification Singh (2005) for perivascular inflammation: 0: no inflammation; 1: one or two concentric rows of inflammatory cells; two, three or more concentric rows of inflammatory cells and 3: accumulation of inflammatory cells between vessels and bronchioles, while the quantification of pulmonary fibrosis is worth Ashcroft scale modified Hübner (2008) [30].

\subsection{Statistical Analysis}

Statistical analyzes were performed using the Stat software. For the variables, saturation, weight and degree of fibrosis calculations were made using the Kruskal-Wallis test, non-parametric data (ANOVA) with post-test for multiple comparisons by Dunn's method.

\section{Results and Discussion}

After expansion, the control flow cytometry showed $98 \%$ of cells expressing CD 90 . In D14, there was a pool of these MSC were infused intravenously into the tail vein at a concentration of $1 \times 10^{6}$ cells/animal in a volume of $200 \mu \mathrm{l}$ saline. No adverse reactions or deaths were identified during the infusion or within 14 days. Histological analyzes were performed by two different experts double-blind study. Intrataqueal instillation of bleomycin at a dose of $1.5 \mathrm{U} / \mathrm{Kg}$ PF determined in $100 \%$ of animals whereas animals had $57.14 \%$ of PF in grade IV. The instillation of intratracheal bleomycin compromised the saturation index of animals and histological analyzes showed an UIP-pattern similar with evidence of marked fibrosis and architectural distortion in a patchy-in- volvement manner. The parameters of weight gain, improved saturation index, recovery macroscopic and microscopic lung tissue were fully achieved in the group treated with MSC-AT. BLM-MSC animals showed a significant reduction in lung fibrosis compared with BLM-W animals, according to histology and morphometry. Remodeled lung structure with contiguous fibrotic areas in BLM-W mice was recovered after MSC therapy by focal fibrotic walls or single fibrotic area. Weight gain, saturation index and macroscopic aspect were improved BLM-MSC group $(\mathrm{p}<0.05)$. Collagen fibers per septal area were decreased in BLM-MSC mice in compared to BLM-W mice $(1.5 \pm 0.1 \times 5.9 \pm 0.4 ; p=0.0005)$. Surprisingly, collagen fibers in CTR-MSC were slightly reduced compared to CTR-W $(1.2 \pm 0.1 \times 1.6 \pm 0.1 ; \mathrm{p}=0.04)$.

The mesenchymal stem cells were obtained from abdominal adipose tissue of 4 Wistar male animals weighing between 250 and $300 \mathrm{~g}$ at 8 weeks of age, who were not part of the 60 animals were divided into 4 experimental groups. The adipose tissue removed medium was $3.35 \mathrm{~g}$ and that after dissociation with collagenase type I use, the lymphomononuclear cells count was $5.3 \times 10^{4} \mathrm{cells} / \mathrm{g}$ of AT, a value considered sufficient to the needs of the experiment, in view of the subsequent amplification stages in culture. The seeded cells were expanded until the 4th passage in the Knockout DMEM, kept in conditions of sterile cultivation.

To prove the phenotypic profile of MSC obtained from adipose tissue in this study were used 3 confirmatory method as indicated by the International Society for Stem Cell: the criteria for adhesion and formation of fibroblast colonies; analysis profile of the cells by flow cytometry and differentiation in 3 tissue strains as Standard Operating Procedure of CELab. For this purpose we used specific culture media conditioned to chondrogenic differentiation, adipogenic and osteogenic (StemPro $\left.{ }^{\circledR}\right)$. The criterion of confirmation for stem cells based on adhesion to plastic in the presence of fibroblast colony forming units was successfully achieved, as photomicrographs inverted phase contrast microscopy (Figure 1).

The second criterion was the analysis of the profile of the cells by flow cytometry, using specific surface markers. The best analyzes are those which occur in the range between 5000 and 10,000 events (cells). The mean of 4 samples were calculated. The CD45, CD34 and CD90. CD44 markers specific for mouse, were executed in two stages: after dissociation, before plating, when the cells were considered lymphomononuclear, and after cultivation. The minimum number of events (cells) analyzed in this experiment was of 8436 and up to 10,000 cells. The maximum number is determined by the equipment itself. Table 2 shows the numerical results of the analysis made. 

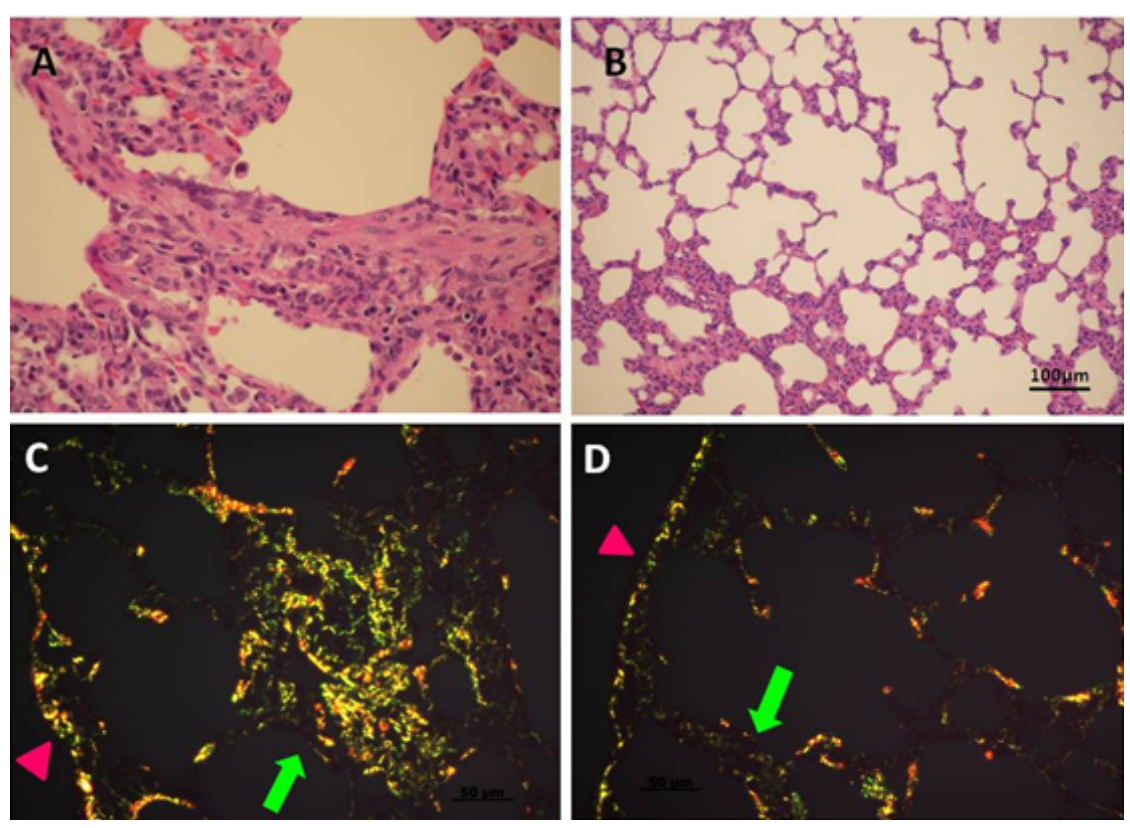

Figure 1. Inverted microscopy Contrast the first criterion of proof of MSC phase: the plastic adherence. $(\mathrm{A})=$ Aspect culture 4 days after seeding (magnification $5 \times) ;(\mathrm{B})=$ Presence of fibroblast colony forming units 15 days after the start of culture $(10 \times$ magnification) and $(\mathrm{C})=$ Presence of fibroblast colony forming units 15 days after the start of culture (magnification $20 \times$ ).

Table 2. Phenotypic profile by Flow Cytometry using markers CD34, CD44, CD45 and CD90.

\begin{tabular}{cccccc}
\hline Markers & Negatif control & CD34 & CD44 & CD45 & CD90 \\
\hline $\begin{array}{c}\text { Average number of events } \\
\text { (cells) analyzed }\end{array}$ & 9013 & 8857 & 10.000 & 8436 & 10.000 \\
$\begin{array}{c}\text { Mean Flurescence } \\
\text { Intensity (\%) }\end{array}$ & 1.83 & 1.70 & 18.59 & $53.38^{*}$ & $17.35^{* *}$ \\
\hline
\end{tabular}

*After enzymatic cleavage, before plating; ${ }^{* *}$ After 21 days in culture specific culture medium (expansion) for MSC.

The distribution of lymphomononuclear cells (LMNC) after enzymatic dissociation by size and granularity scatter plot is available in Figure 2(A). In Figure 2(B), the cell population without specific marker, which is considered as negative control. The bar with the designation M1 defines the area corresponding to the peak of cells expressing markers for positive MSC. In C, the result of which CD34 expression was observed reactivity of $1.70 \%$ on average, a result expected for this sample.

Te third profile verification criteria of the MSC-AT used was the ability to differentiate into three different tissues. It was proved the capabilities of amplified cells to differentiate with conditioned media into chondrocytes, osteoblasts and adipocytes. The verification was performed by immunohistochemistry method using specific markers.

\subsection{Weight Variation of Animals}

The literature indicates the weight loss of the animals submitted to intratracheal instillation with bleomycin. To verify this finding, the animals, kept under identical conditions, were weighed in three times: D0, D14 and D28. The working hypothesis was that the bleomycin-induced pulmonary fibrosis decrease the weight of the animals which could be re-established with the MSC therapy. Statistical analysis showed significant differences, $p$ $<0.0001$ in D0, since there was no decision to pair the animals by weight. Compared the weight of the animal G1BLM-W groups and G2 CTR-W, there was no statistical difference, $p>0.05$, as well as between G3 BIMMSC and G4 CTR-MSC. Comparisons between different groups on D +28 also did not identify statistically significant difference. 

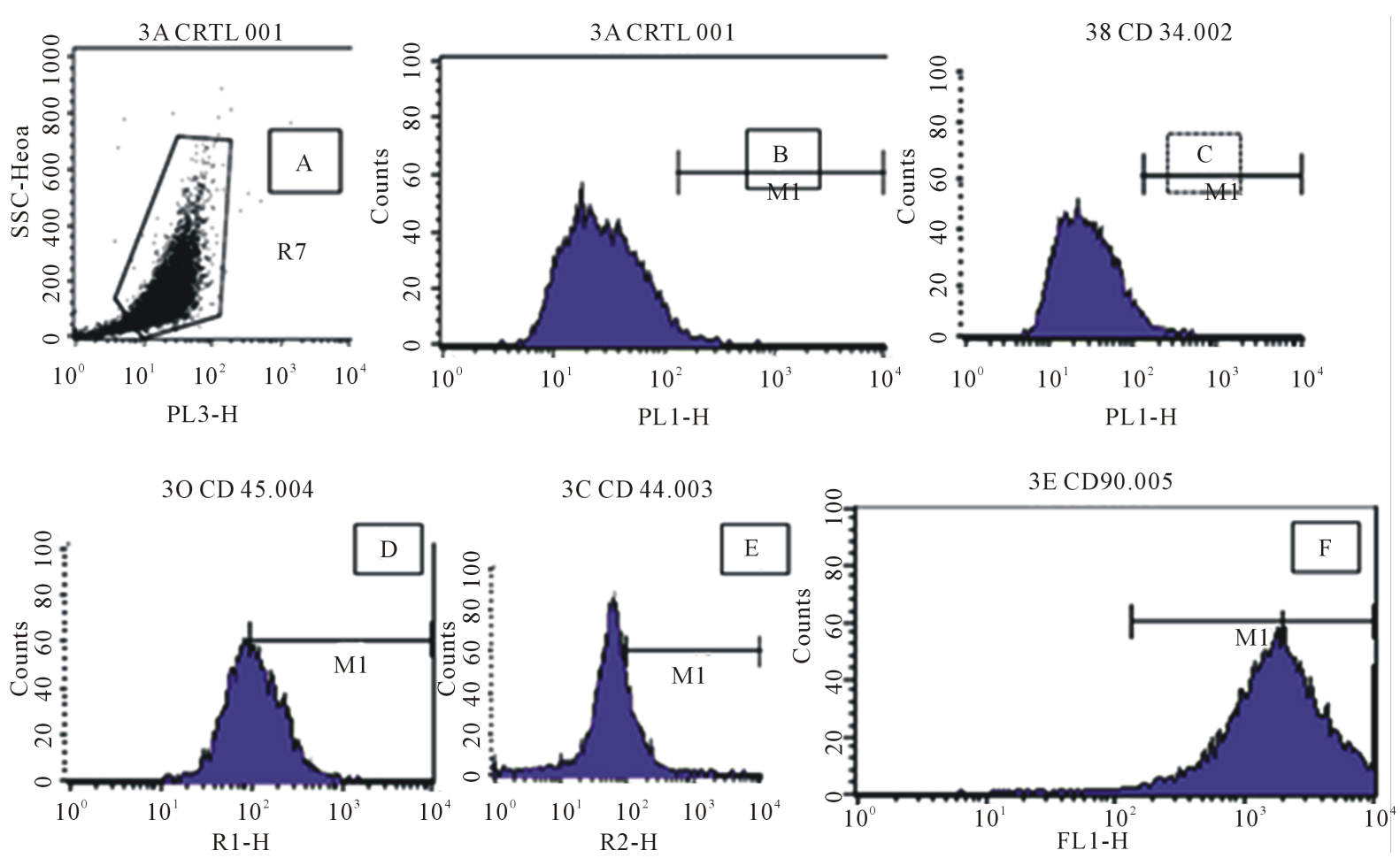

Figure 2. Analysis by flow cytometry with fluorescent markers. $(\mathrm{A})=$ Dispersion graph of LMNC; $(\mathrm{B})=$ negative control; $(\mathrm{C})=\mathrm{CD} 34 ;(\mathrm{D})=\mathrm{CD} 45$ pre-plating; $(\mathrm{E})=(\mathrm{F})=\mathrm{CD} 44$ and $\mathrm{CD} 90$ post amplification in culture.

Martinez (2008) publishes the isolated use of bleomycin is associated with significant loss of total body weight and a high mortality rate (40\%) compared to control groups [31]. Data from this study do not corroborate the results of that author, because the mortality rate in this study was low and there was no statistically significant difference with respect to weight. During the 28 days of monitoring were registered two losses in different groups $(2 / 60$ or $3.33 \%)$ at the time of instillation of bleomycin, can be related to the process of anesthesia or chemotherapy itself. No deaths among the animals in the days following the injection of bleomycin, or systemic infectious process was not registered.

\subsection{Variation Saturation}

To monitor the induced fibrosis was used the saturation measurement with pediatric equipment setting the sense in the proximal portion of the tail. The formulated hypothesis was that it would decrease with the installation of the fibrosis process and that there would be a recovery of saturation indexes with use of the MSC-AT. This fact would be an indicator of clinical and anatomical and pathological improvement. The data confirmed the fall of the saturation index in animals in which was instilled bleomycin (G1BLM-W and G3 BLM-MSC). In D0, statistically significant differences were recorded between groups, as expected $(p=0.6313)$. Statistical analyzes of the saturation measurement for D14 between G2/G2 and G3/G4 show significant differences with $\mathrm{p}<0.05$. D $+28 \mathrm{p}<$ 0.049 , very significant.

The data indicating the supremacy of the control group G2 CTR-W on the other, including on the G4 CTR-MSC. This can be explained by the fact that the animals were handled in conventional animal facility without filtered air. However, the recovery of saturation measurement indexes can be observed in the groups, according to the moment to be analyzed (14 + D or D +28) even in G1 BLM-W. This result is expected because King (2011) indicates that one of the limitations of pulmonary fibrosis model with the use of bleomycin is their potential spontaneous recovery, however, it is the most used model [32] [33]. The decision, in this experiment, to sacrifice 28 days later, was basically made on this fact. That is, to the MSC intervention before the onset of spontaneous regression. In fact, many other authors critical to IPF animal models, which do not reflect faithfully the intricate mechanism that occurs in humans [34]-[36]. 


\subsection{Macroscopic Examination}

Macroscopic analysis of the lung took into account the following characteristics: architecture, proportion, and surface staining and confirmed the expected changes and described in the literature [30].

For group 1 (BLM-W), which was induced fibrosis and no infusion of MSC-AT, from the original 15 animals occurred in D0 loss of them because the animal was at death, two minutes after instillation of bleomycin. Of the 14 animals alive at the end of the experiment (D28) analysis showed macroscopic changes in $100 \%$ of the lungs, and the same could be divided into 4 groups according to the degree of progression of macroscopic lesions identified, Figure 3.

It was identified only 1rat/14 (7.14\%) showing few signs on surface and kept the other macroscopic characteristics of a healthy lung, Figure 3(A).

Two animals showed a moderate or intermediate II $(\mathrm{N}=2 / 14)$ corresponding to $14.28 \%$ of the group with the entire surface plates, color change, but maintained the proportionality and lung architecture. Touch the lung tissue showed friable, Figure 3(B).

In the classification degree III or advanced $(\mathrm{N}=3 / 14$, or $21.42 \%)$ the lungs showed plates by entire surface, obvious change of color, observing loss of proportion and of architecture pulmonary, beyond the tissue be quite friable, Figure 3(C).

The most animals (57.14\%) developed a fibrosis grade IV, advanced with complications (8/14). Watchlisted up plates per entire surface, with alteration staining, occurring loss of proportion and architecture, tissue quite crispy being that in 6 animals were detected various points of necrosis, Figure 3(D).
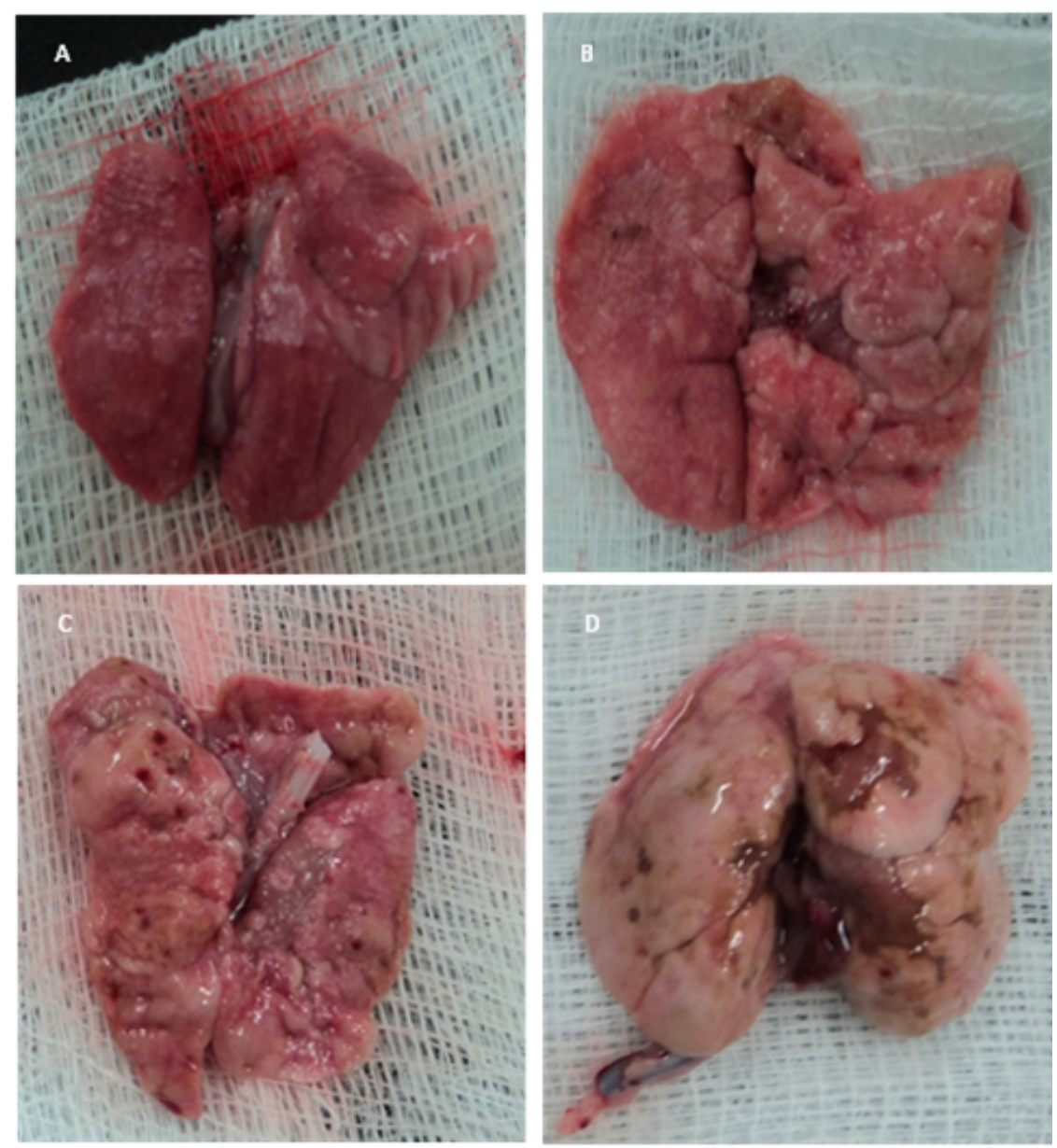

Figure 3. Classification of degrees of fibrosis according to the macroscopic examination of the lungs of animals in the G1 (BLM-W in D28. A = grade I (mild); B = moderate (intermediate); $\mathrm{C}=$ advanced degree $\mathrm{III}$ and $\mathrm{D}=$ advanced degree with complications. 
For the Group 2 (CTR-W), therefore for these pets not there was the induction of fibrosis and neither the use of MSC-AT. This group corresponds to the group control, not having been recorded any intercurrence. They were evaluated the 15 animals of group control being that the lungs presented preservation of architecture, proportion, coloration and surface, Figure 4.

The experimental group G3 (BLM-MSC, the animals suffer PF induced tracheal instillation of bleomycin, they had on Day +14 infusion $1 \times 10^{6}$ MSC-AT infused by tail vein. This group had the loss of one animal in D0, 1 minutes after instillation of bleomycin, a fact similar to that in the G1.

In the lungs 14 of the live animals until the end of the experiment (day +28$)$ were observed in $100 \%$ of specimens: no surface boards, preservation architecture and proportion and a non-friable parenchyma. The brightly pink color with brighter surface drew attention. In $50 \%$ of cases, besides the aforementioned characteristics it was noticeable with some small necrotic spots surrounding apparent recovery, Figure 5.

In group 4 (CTR-MSC) in which the animals were exposed to the same stress handling in D0, the saline intratracheal instillation and D +14 received similar amounts of MSC relative to the G3 group was also not observed any death among the 15 in the group. The lungs of animals in this group showed preservation of architecture and proportion and more intense pink color, brighter and as expected surface, the tisssue was not friable, Figure 6.

\subsection{Pulmonary Histological Analysis}

This analysis was conducted in a double-blind study by interpreting two expert pathologists in lung histopathology. The analyzes involved classical hematoxylin-eosin and cytochemistry of Picrosirius. The perivascular

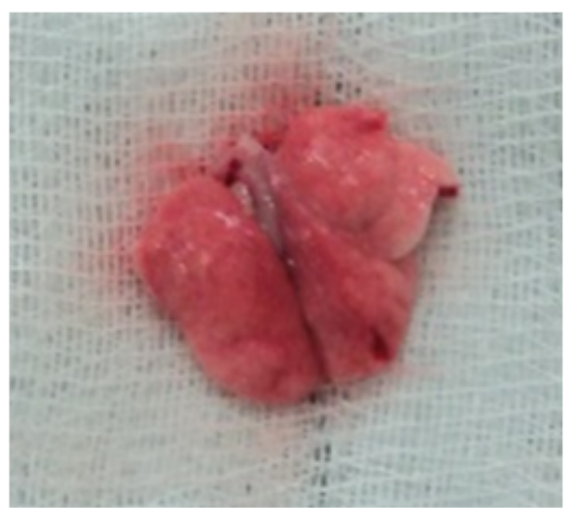

Figure 4. Animal lung macroscopic appearance of a member of the G1 Group (CTRW). Normal control.
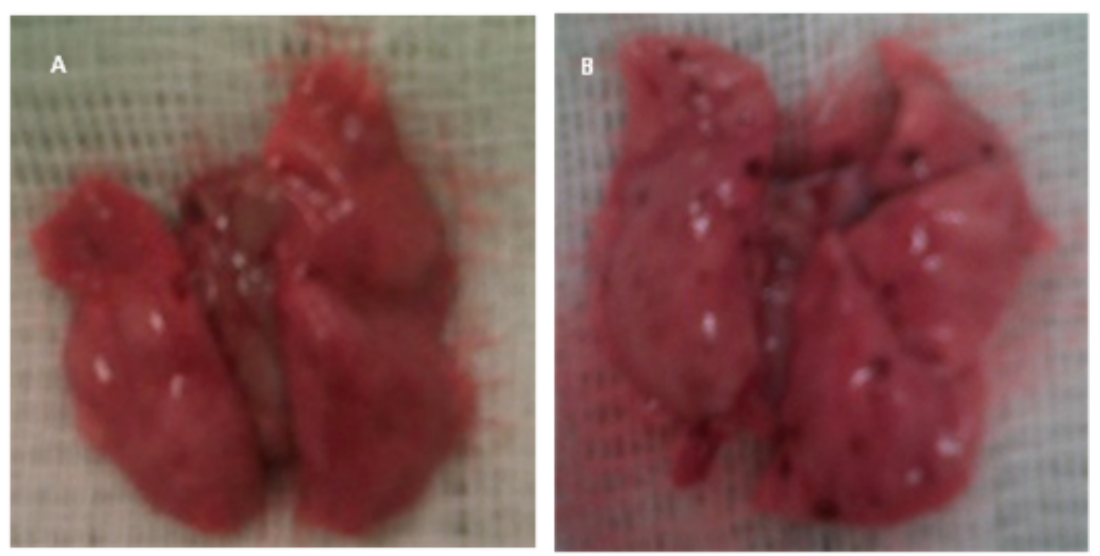

Figure 5. Macroscopic analysis of the lungs of animals in group G3 (BLM-MSC) in D28 with architecture, proportion and preserved color. (A) and (B) represent dif- ferents animals. $\mathrm{B}$ is observed necrosis points with surrounding tissue recovered. 


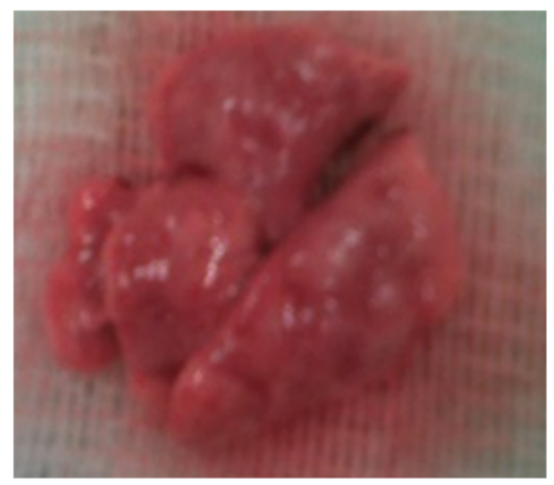

Figure 6. Macroscopic analysis of the lungs of the animals of the G4 group (CTRMSC) with normal tissue architecture, proportion and normal coloring.

inflammation assessment used the semi-quantitative histopathologic evaluation system for perivascular inflammation as described by Singh [35] described in materials and methods, while quantification of pulmonary fibrosis is worth Ashcroft scale modified Hübner [30].

In G1 (BLM-W) notices a pattern of diffuse pulmonary fibrosis, tending to subpleural region, but not outright mass formation (except case 15), but a feature presentation sacular parenchymal remodeling, where the alveoli show large septal thickening forming aberrant nonfunctional sac-like structure. Inflammation is sharp and primarily affects the peripheral vessels, which show large medial hypertrophy. There frank bronchitis and bronchiolitis with epithelial destruction intense (Figure 7).

Group 2: it is observed a more diffuse pattern with dense fibrosis, but with peribronchial and bronchiolar focus, beyond subpleural. The parenchymal remodeling affects almost all septa and is observed on the border between the fibrotic mass areas and slightly thickened fibrotic septa-like structures fibroblastic foci, in which occurs the myofibroblast activation and progression of lung fibrogenesis. Inflammation is mild to moderate and eventually accompanying vessels, which are often with medial hypertrophy. It is noticed Frank bronchitis and bronchiolitis with intense epithelial destruction (Figure 8).

Group 3: In this group there was a significant reduction of fibrosis, but in most cases it is noticed even isolated fibrous masses (Figure 9). The septa sometimes present with thin and delicate usual structural sometimes show different degrees of thickening to form true dense fibrous masses. Not observed abnormal alveolar septa or abnormal septal architecture in preserved areas. It is noted macrophages with finely granular cytoplasm of bluishbetween some fibrotic and perivascular regions, may represent some exogenous pigment and/or bacteria or other. Inflammation is centered on the axis-bronchial vascular characterized in bronchoalveolar mononuclear cells and epithelial-tropism. Bronchopneumonia was identified in some cases by inflammatory infiltrate intra-bronchial neutrophilic intraepithelial abscess and its consequent organizing pneumonia. It is noted medial hypertrophy of the pulmonary arteries and arterioles, perhaps less so than the other groups. Interestingly there was "hyperplasia" of its endothelial cells, which show very well defined and "healthy". There focal mesothelial hyperplasia, usually associated with fibrotic areas.

Group 4: we can see a significant attenuation of fibrosis, without the formation of fibrous masses except the case 11. Most of the septa has his usual delicate look or with minimal changes. Yet other areas there is a greater thickening and eventually with the presence of small fibrotic nodules. Inflammation is moderate with variable perivascular involvement. Note to intense chronic bronchitis and bronchiolitis in activity, indicating major antigenic stimulus. It is observed for signs of pulmonary hypertension, but appear to a lesser degree (Figure 10).

\subsection{Histological Analysis in Masson's Picrosirius}

The method of staining by Masson's Picrosirius is the color red by Sirius Red collagen protein found in collagen fibers, reticular, cartilage and in basement membranes (Figure 11). When combined with polarizing microscopy, allows collagen viewing by the parallel organization of tropocollagen molecules. Type I collagen fibers present color ranging from red to bright yellow with intense birefringence. Collagen type II presents less intense birefringence and pale yellow color. Type III collagen appears as delicate fibers of greenish. After statical analysis, all the results are represented in Figure 12. 

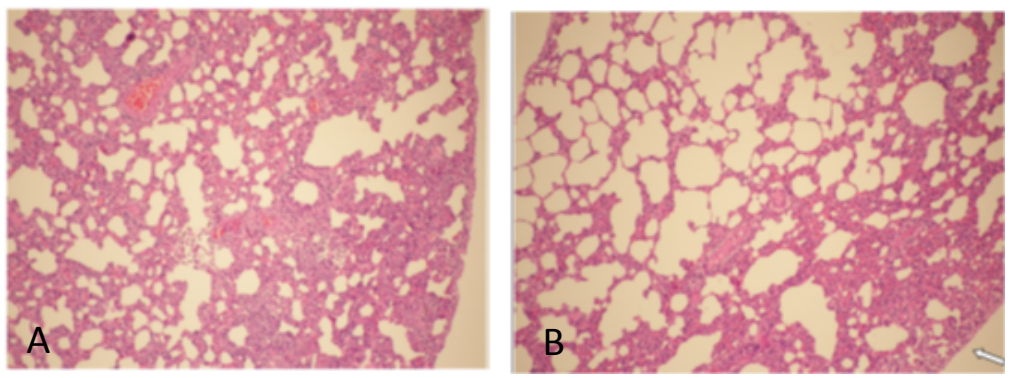

Figure 7. Pulmonary fibrosis pattern-histological appearance with Histological, representative of the G1 (BLM-W). A = Septal thickening diffuse untrained fibrotic masses, 10×; B = Sepptal thickening diffuse affecting more subpleural region (arrow). 10×.
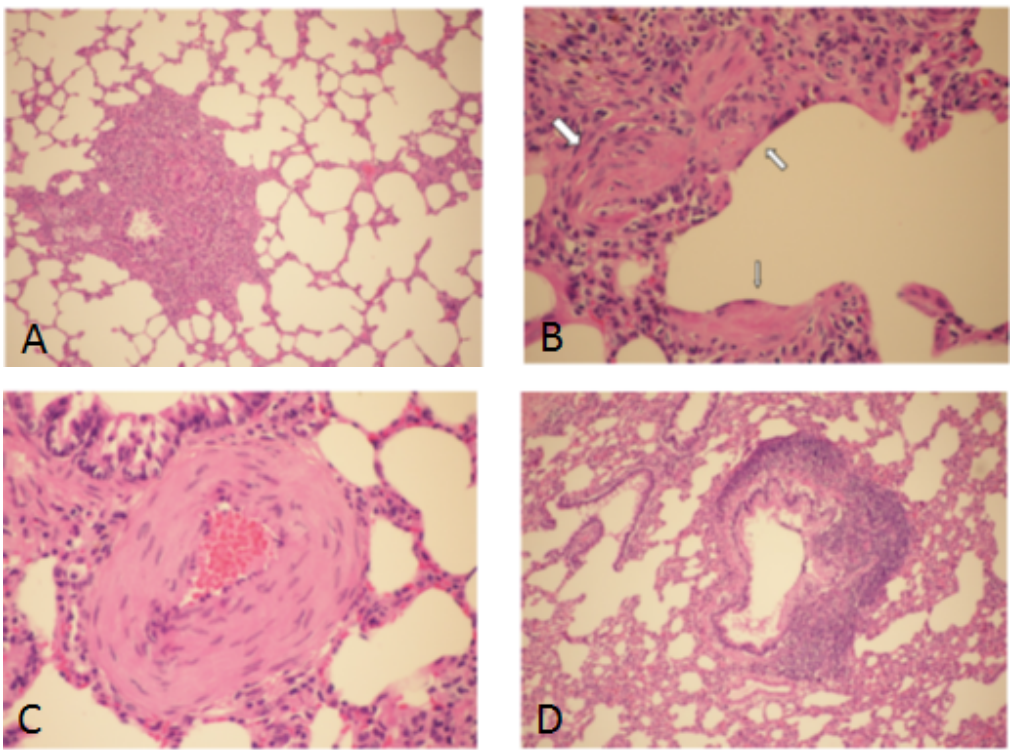

Figure 8. Diffuse pattern with dense fibrosis em Group 2. (A) = Most peribronchial fibrotic involvement, however note the alveolar septa are abnormally thickened. $10 \times ;(B)=$ Matrix structure in which myofibroblasts are active, remembering fibroplastic focus of Idiopathic Pulmonary Fibrosis (arrow). 40×; (C) = Hypertrophy of the middle layer of peripheral vessels. 40×; (D) = Active chronic bronchitis with destruction of the epithelium layer and muscle. 10×.
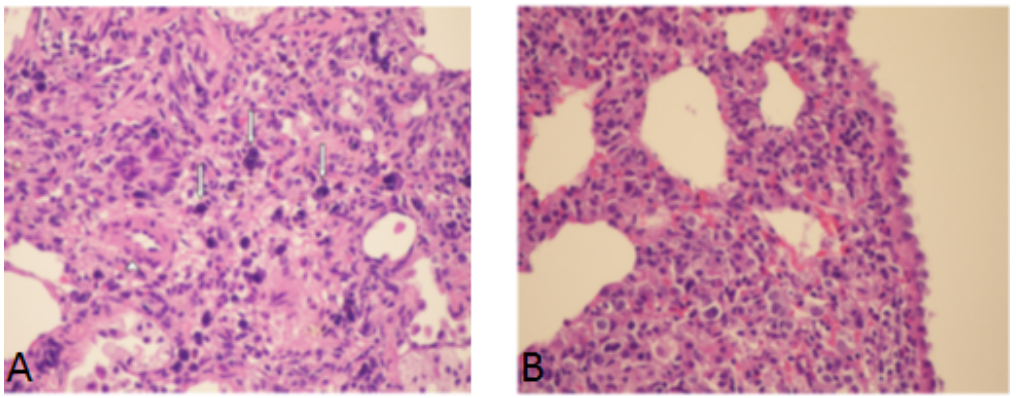

Figure 9. Fibrous mass consists of (myo) fibroblasts, extracellular matrix and vessels (group 3 ). (A) = Note the vessel with moderate hypertrophy of the middle and preserved endothelial cells (arrowhead). Macrophages microvacuolized basophilic are distributed by mass (arrow). 20×; (B) = Mesothelial hyperplasia adjacent the fibrotic area. $20 \times$. 

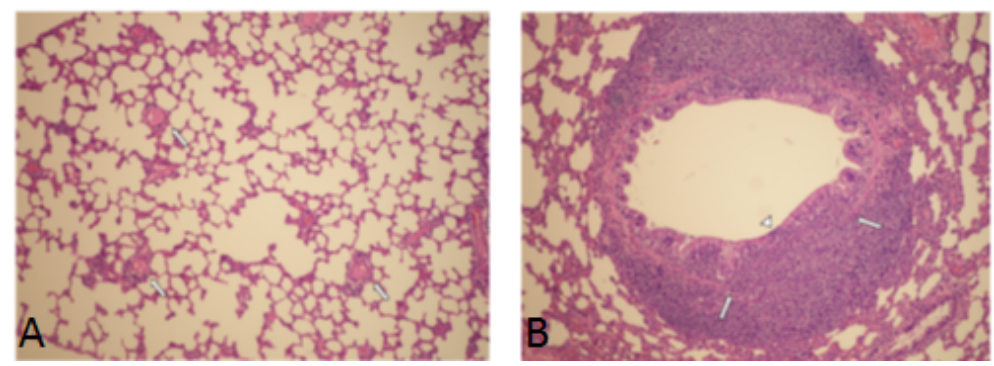

Figure 10. Histological aspects Group 4. (A) = Alveolar septa of normal fine delicate aspect or with minimal changes the interstitial component. Note the intense perivascular inflammatory infiltrate (arrows). 10×; (B) = Terminal bronchioles and respiratory bronchioles usual appearance. $10 \times$.
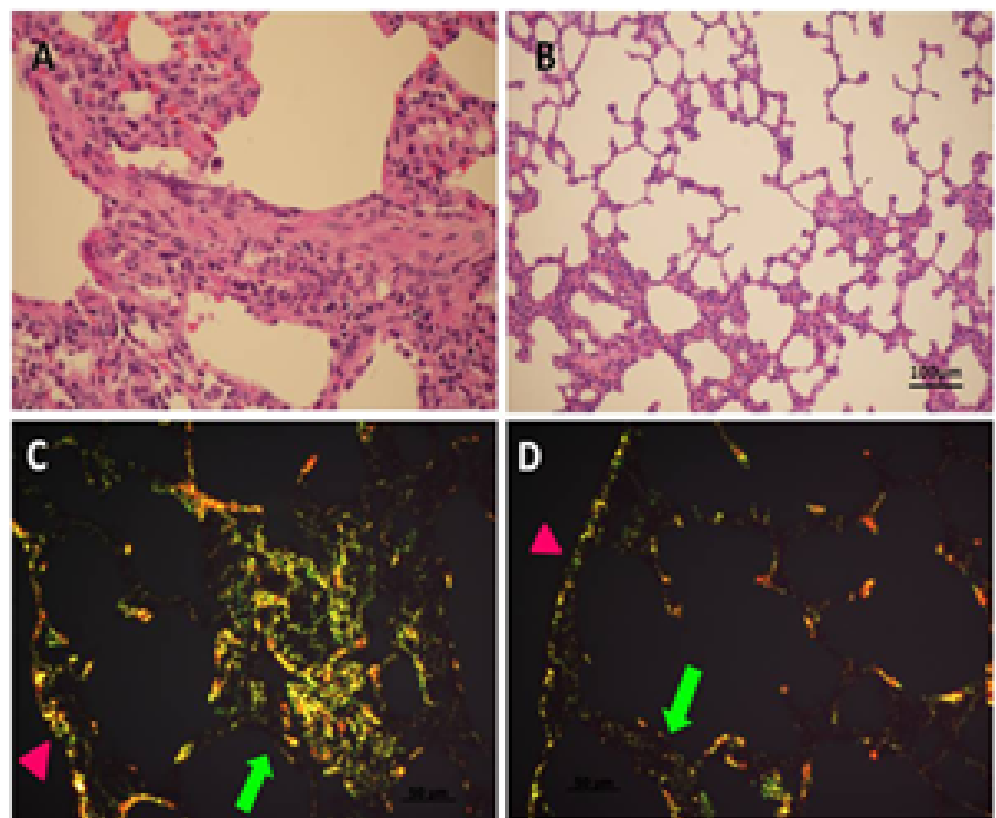

Figure 11. H\&E (A), (B) and Pricrosirius Red (C), (D) stained sections and morphometric analysis of BLM-W (A), (C) and BLM-MSC (B), (D). Note the fibrotic mass $(\mathrm{C}$, arrow) and pleural thickening $(\mathrm{C}$, arrowhead) in BLM-W group in contrast to the fibrotic wall $(\mathrm{D}$, arrow) and normal pleura $(\mathrm{D}$, arrowhead) em BLM-MSC group.

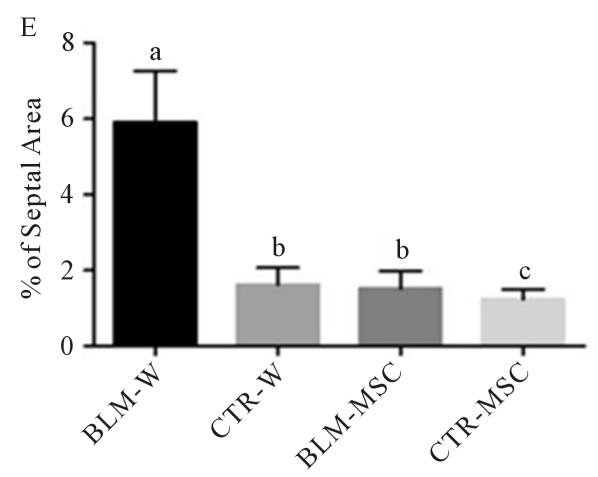

Figure 12. All the results are presented as mean and associated standard errors and different small letters (a-c) denote a significant difference between groups $(\mathrm{p}<0.05)$. 


\section{Conclusion}

MSC from adipose tissue is an effective therapy to decrease collagen synthesis and expression in late stage of bleomycin-induced pulmonary fibrosis model, which may contribute to new therapeutic targets.

\section{Acknowledgements}

Carlos Roberto Gonçalves Lima for their support in animal care and Cell Engineering Laboratory staff.

\section{Competing Interests}

No competing interests.

\section{Authors' Contributions}

Renato Gonçalves Felix: pulmonologist founder and conductor of the proposal;

Alexandre Todorovic Fabro: senior thoracic pathologist responsible for the audit and review of histomorphometric analysis;

Josy Campanhã Vicentini-Oliveira: veterinarian who advised and conducted experiments on animals and cell culture;

Ednelson Henrique Bianchi: zootecnist assist the technical procedures with animals;

Marjorie de Assis Golim: expert for flow cytometry;

Ondina Silvia Cotrim: academic support assistant in cell culture procedures;

João Tadeu Ribeiro-Paes: Data analysis and discussion;

Elenice Deffune: coordinator of cell engineering laboratory and mentor project.

\section{References}

[1] Meltzer, E.B. and Noble, P.W. (2008) Idiopathic Pulmonary Fibrosis. Orphanet Journal of Rare Diseases, 3, 8. http://dx.doi.org/10.1186/1750-1172-3-8

[2] Gross, T.J. and Hunninghake, G.W. (2001) Idiopathic Pulmonary Fibrosis. The New England Journal of Medicine, 345, 517-525. http://dx.doi.org/10.1056/NEJMra003200

[3] Moeller, A., Ask, K., Warburton, D., Gauldie, J. and Kolb, M. (2008) The Bleomycin Animal Model: A Useful Tool to Investigate Treatment Options for Idiopathic Pulmonary Fibrosis? The International Journal of Biochemistry \& Cell Biology, 40, 362-382. http://dx.doi.org/10.1016/j.biocel.2007.08.011

[4] Klingsberg, R., Mutsaers, S. and Lasky, J. (2010) Current Clinical Trials for the Treatment of Idiopathic Pulmonary Fibrosis. Journal of Asian Pacific Society of Respirology, 15, 19-31. http://dx.doi.org/10.1111/j.1440-1843.2009.01672.x

[5] Ley, B., Collard, H.R. and King Jr., T.E. (2011) Clinical Course and Prediction of Survival in Idiopathic Pulmonary Fibrosis. American Journal of Respiratory and Critical Care Medicine, 183, 431-440. http://dx.doi.org/10.1164/rccm.201006-0894CI

[6] Pereira, C.A., Malheiros, T., Coletta, E.M., Ferreira, R.G., Rubin, A.S., Otta, J.S., et al. (2006) Survival in Idiopathic Pulmonary Fibrosis-Cytotoxic Agents Compared to Corticosteroids. Respiratory Medicine, 100, 340-347. http://dx.doi.org/10.1016/j.rmed.2005.05.008

[7] Taskar, V.S. and Coultas, D.B. (2006) Is Idiopathic Pulmonary Fibrosis an Environmental Disease? Proceedings of the American Thoracic Society, 3, 293-298. http://dx.doi.org/10.1513/pats.200512-131TK

[8] Selman, M., King, T.E. and Pardo, A. (2001) Idiopathic Pulmonary Fibrosis: Prevailing and Evolving Hypothesis about Its Pathogenesis and Implications for Therapy. Annals of Internal Medicine, 134, 136-151. http://dx.doi.org/10.7326/0003-4819-134-2-200101160-00015

[9] Raghu, G., Collard, H.R., Egan, J.J., Martinez, F.J., Behr, J., Brown, K.K., et al. (2011) An Official ATS/ERJ/JRS/ ALAT Statement: Idiopathic Pulmonary Fibrosis: Evidence-Based Guidelines for Diagnosis and Management. American Journal of Respiratory and Critical Care Medicine, 183, 788-824. http://dx.doi.org/10.1164/rccm.2009-040GL

[10] Noth, I. and Martinez, F.J. (2007) Recent Advances in Idiopathic Pulmonary Fibrosis. Chest, 132, 637. http://dx.doi.org/10.1378/chest.06-1927

[11] Harari, S. and Caminati, A. (2010) IPF: New Insight on Pathogenesis and Treatment. Allergy, 65, 537-553. http://dx.doi.org/10.1111/j.1398-9995.2009.02305.x 
[12] Kim, D.S. (2006) Interstitial Lung Disease in Rheumatoid Arthritis: Recent Advances. Current Opinion in Pulmonary Medicine, 12, 346-353. http://dx.doi.org/10.1097/01.mcp.0000239552.55326.ee

[13] Collard, H.R., King Jr., T.E., Bartelson, B.B., Vourlekis, J.S., Schwarz, M.I. and Brown, K.K. (2003) Changes in Clinical and Physiologic Variables Predict Survival in Idiopathic Pulmonary Fibrosis. American Journal of Respiratory and Critical Care Medicine, 168, 538-542. http://dx.doi.org/10.1164/rccm.200211-13110C

[14] Zhang, Y., Khan, D., Delling, J., et al. (2012) Mechanisms Underlying the Osteo- and Adipo-Differentiation of Human Mesenchymal Stem Cells. The Scientific World Journal, 2012, 1-14. http://dx.doi.org/10.1100/2012/793823

[15] Schreml, S., Babilas, P., Fruth, S., et al. (2009) Harvesting Human Adipose Tissue-Derived Adult Stem Cells: Resection versus Liposuction. Cytotherapy, 11, 947-957. http://dx.doi.org/10.3109/14653240903204322

[16] Krause, D.S., Theise, N.D., Collector, M.I., et al. (2001) Multi-Organ, Multi-Lineage Engraftment by a Single Bone Marrow-Derived Stem Cell. Cell, 105, 369-377. http://dx.doi.org/10.1016/S0092-8674(01)00328-2

[17] Loebinger, M.R. and Janes, S.M. (2007) Stem Cells for Lung Disease. Chest, 132, 279-285. http://dx.doi.org/10.1378/chest.06-2751

[18] Gimble, J.M., Guilak, F. and Bunnell, B.A. (2010) Clinical and Preclinical Translation of Cell-Based Therapies Using Adipose Tissue-Derived Cells. Stem Cell Research \& Therapy, 1, 19. http://dx.doi.org/10.1186/scrt19

[19] King Jr., T.E., Pardo, A. and Selman, M. (2011) Idiopathic Pulmonary Fibrosis. The Lancet, 378, 1949-1961. http://dx.doi.org/10.1016/S0140-6736(11)60052-4

[20] Liu, Z.J., Zhuge, Y. and Velazquez, O.C. (2009) Trafficking and Differentiation of Mesenchymal Stem Cells. Journal of Cellular Biochemistry, 106, 984-991. http://dx.doi.org/10.1002/jcb.22091

[21] Körbling, M., Estrov, Z. and Champlin, R. (2003) Adult Stem Cells and Tissue Repair. Bone Marrow Transplant, 32, S23-S24. http://dx.doi.org/10.1038/sj.bmt.1703939

[22] Kørbling, M. and Estrov, Z. (2003) Adult Stem Cells for Tissue Repair-A New Therapeutic Concept? The New England Journal of Medicine, 349, 570-582. http://dx.doi.org/10.1056/NEJMra022361

[23] Punithavathi, D., Venkatesan, N. and Babu, M. (2000) Curcumin Inhibition of Bleomycin-Induced Pulmonary Fibrosis in Rats. British Journal of Pharmacology, 131, 169-172. http://dx.doi.org/10.1038/sj.bjp.0703578

[24] Umezawa, H., Suhara, Y., Takita, T. and Maeda, K. (1996) New Antibiotics, Bleomycin A and B. Journal of Antibiotics, 19, 200-209.

[25] Thrall, R.S., McCormick, J.R., Jack, R.M., McReynolds, R.A. and Ward, P.A. (1979) Bleomycin-Induced Pulmonary Fibrosis in the Rat: Inhibition by Indomethacin. The American Journal of Pathology, 95, 117-130.

[26] Özyurt, H., Sögut, S., Yildirim, Z., Kart, L., Iraz, M., Amutçu, F., Temel, I., Özen, S., Uzun, A. and Akyol, Ö. (2004) Inhibitory Effect of Caffeic Acid Phenethyl Ester on Bleomycine-Induce Lung Fibrosis in Rats. Clinica Chimica Acta, 339, 65-75. http://dx.doi.org/10.1016/j.ccen.2003.09.015

[27] Cutroneo, K.R. (2006) Evidence for TGF-Betal and Bleomycin Intracellular Signaling through Autocrine Regulation of Smad 3 Binding to the Proximal Promoter of the Smad 7 Gene. Journal of Cellular Biochemistry, 97, 933-939. http://dx.doi.org/10.1002/jcb.20594

[28] Hubner, R.H., Gitter, W., El Mokhtari, N.E., Mathiak, M., Both, M., Bolte, H., et al. (2008) Standardized Quantification of Pulmonary Fibrosis in Histological Samples. BioTechniques, 44, 507-511, 514-517.

[29] Martinez, J.A., Ramos, S.G., Meirelles, M.S., Verceze, A.V., Arantes, M.R. and Vannucchi, H. (2008) Effects of Quercetin on Bleomycin-Induced Lung Injury: A Preliminary Study. Jornal Brasileiro de Pneumologia, 34, 445-452. (In Portuguese)

[30] King Jr., T.E., Behr, J., Brown, K.K., du Bois, R.M., Lancaster, L., de Andrade, J.A., et al. (2008) BUILD-1: A Randomized Placebo-Controlled Trial of Bosentan in Idiopathic Pulmonary Fibrosis. American Journal of Respiratory and Critical Care Medicine, 177, 75-81. http://dx.doi.org/10.1164/rccm.200705-732OC

[31] Kumar, V., Abbas, A.K. and Aster, J.C. (2015) Robbins \& Cotran Pathologic Basis of Disease. 9th Edition, Elsevier, Philadelphia.

[32] Singh, B., Shinagawa, K., Taube, C., Gelfand, E.W. and Pabst, R. (2005) Strain-Specific Differences in Perivascular Inflammation in Lungs in Two Murine Models of Allergic Airway Inflammation. Clinical and Experimental Immunology, 141, 223-229. http://dx.doi.org/10.1111/j.1365-2249.2005.02841.x

[33] Raghu, G., Depaso, W.J., Cain, K., Hammar, S.P., Wetzel, C.E., Dreis, D.F., et al. (1991) Azathioprine Combined with Prednisone in the Treatment of Idiopathic Pulmonary Fibrosis: A Prospective Double-Blind, Randomized, PlaceboControlled Clinical Trial. The American Review of Respiratory Disease, 144, 291-296. http://dx.doi.org/10.1164/ajrccm/144.2.291

[34] Raghu, G., Brown, K.K., Costabel, U., Cottin, V., du Bois, R.M., Lasky, J.A., et al. (2008) Treatment of Idiopathic Pulmonary Fibrosis with Etanercept: An Exploratory, Placebo-Controlled Trial. American Journal of Respiratory and Critical Care Medicine, 178, 948-955. http://dx.doi.org/10.1164/rccm.200709-1446OC 
[35] Singh, B., Shinagawa, K., Taube, C., Gelfand, E.W. and Pabst, R. (2005) Strain-Specific Differences in Perivascular Inflammation in Lungs in Two Murine Models of Allergic Airway Inflammation. Clinical and Experimental Immunology, 141, 223-229. http://dx.doi.org/10.1111/j.1365-2249.2005.02841.x

[36] Antó, J.M. and Cullinan, P. (2001) Clusters, Classification and Epidemiology of Interstitial Lung Diseases: Concepts, Methods and Critical Reflections. European Respiratory Journal, 32, 101-106.

\section{Abbreviations}

IPF: Idiopathic pulmonary fibrosis

MSC: Mesenchymal Stem Cells

DMEM: Dulbecco's Modified Eagle Medium: Nutrient Mixture F-12

BLM-W: Wistar mice instilled intratracheal bleomycin

CTR-W: Wistar mice Control group (placebo)

CTR-MSC: Wistar mice control group treated with Mesenchymal Stem Cells

BLM-MSC: Wistar mice instilled intratracheal bleomycin and treated with mesenchymal stem cells

ATS/ERS: American Thoracic Society/European Respiratory Society 